\title{
ANALYSIS OF SOOT SURFACE GROWTH PATHWAYS USING PUBLISHED PLUG-FLOW REACTOR DATA WITH NEW PARTICLE SIZE DISTRIBUTION MEASUREMENTS AND PUBLISHED PREMIXED FLAME DATA
}

\author{
DAVID F. KRONHOLM AND JACK B. HOWARD \\ Department of Chemical Engineering \\ Massachusetts Institute of Technology \\ 77 Massachusetts Avenue \\ Cambridge, MA 02139, USA
}

\begin{abstract}
Soot particle size distributions were measured using thermophoretic sampling, followed by electron microscopy, at different residence times during soot formation in a plug-flow reactor (PFR) under two sets of premixed $\mathrm{C}_{2} \mathrm{H}_{4}$ /air combustion conditions ( $1 \mathrm{~atm}$, equivalence ratio 2.2 , and $1520 \mathrm{~K}$ and $1620 \mathrm{~K}$ ) for which published concentration profiles of gas species and soot mass are available. The data were used to calculate the Harris global rate coefficient, $k_{\text {Harris }}$, for $\mathrm{C}_{2} \mathrm{H}_{2}$ addition to soot. The $\mathrm{C}_{2} \mathrm{H}_{2}$-soot reactivity as indicated by $k_{\text {Harris }}$ is found to oscillate significantly and to show a net increase with residence time in the PFR, neither of which behaviors would be expected if $\mathrm{C}_{2} \mathrm{H}_{2}$ were actually the growth reactant. In contrast, use of the data to compute the global collision efficiency for dichloromethane (DCM) soluble polycyclic aromatic hydrocarbon $(\mathrm{PAH})$ addition to soot, $\gamma_{\mathrm{PAH}-\mathrm{soot}}$, gives a soot reactivity with no net increase with residence time, and smaller oscillations explainable by the observation that higher molecular weight $\mathrm{PAH}$ fluctuate more than the total DCM soluble fraction. Interpreting the Harris $\mathrm{C}_{2} \mathrm{H}_{2}$ addition mechanism as a globalization of the PAH addition mechanism with constant soot reactivity indicates that the oscillations and net increase of the Harris $\mathrm{C}_{2} \mathrm{H}_{2}$-soot reactivity are consistent with the variations in the concentration of the PAH reactants and particle size. Also consistent with these results are previous observations that the Harris $\mathrm{C}_{2} \mathrm{H}_{2}$-soot reactivity in premixed flames decreases sharply with residence time. Analysis here of published data from premixed one-dimensional $\mathrm{C}_{2} \mathrm{H}_{2} / \mathrm{O}_{2}$ and $\mathrm{C}_{6} \mathrm{H}_{6} / \mathrm{O}_{2} /$ Ar flames shows that the declining $\mathrm{C}_{2} \mathrm{H}_{2}$-soot reactivity agrees with the decline in the concentration of $\mathrm{PAH}$ reactants and increase in soot particle size, assuming a constant $\mathrm{PAH}$-soot reactivity.
\end{abstract}

\section{Introduction}

Data sets on sooting flames that include time-resolved measurements of both particle size distribution and number density as well as concentrations of a sufficient number of the main gas species and temperature [1-6] are vital to the development of detailed models of soot formation. Soot formation in a plug-flow reactor (PFR) has been studied extensively under sooting conditions [7-10], and concentration data for light gas species, individual polycyclic aromatic hydrocarbons (PAH), total PAH (dichloromethane [DCM] soluble compounds) mass, and soot (DCM insolubles) mass have been obtained for various equivalence ratios $(\phi)$, temperatures $(T)$, and fuel additives. The PFR has a simple reactor geometry, permitting computations with large kinetics models (500-1000 reactions, 100-300 species) to be run in minutes, as opposed to hours for premixed flames, and without the uncertainty of diffusion parameters. However, the literature does not include soot particle size measurements for any of the data sets, thus leaving the soot inadequately characterized and hampering the study of elementary processes of soot formation. To address this need, soot particle size distributions were measured in the PFR in the present study under two of the previously studied sets of conditions and the results were used with the previous PFR [7-10] and other flame [1-6] data to analyze pathways of soot surface growth.

\section{Experimental Data}

Soot samples for transmission electron microscopy (TEM) were collected using the thermophoretic sampling [11] apparatus of Feitelburg [12], from premixed $\mathrm{C}_{2} \mathrm{H}_{4}$ /air combustion in a 2 in. diameter PFR [8-10] under two sets of conditions (1 atm, $\phi$ $=2.2$, and $1620 \mathrm{~K}$ and $1520 \mathrm{~K}$ ) for which concentration profiles of light gas species, total PAH mass, and soot mass had already been measured $[9,13]$. The soot particles were deposited on TEM grids inserted into the PFR at different axial distances or residence times, for flame exposure times of 100 $200 \mathrm{~ms}$. This range, which gave the optimal soot coverage of the grid, was identified in tests of exposure 

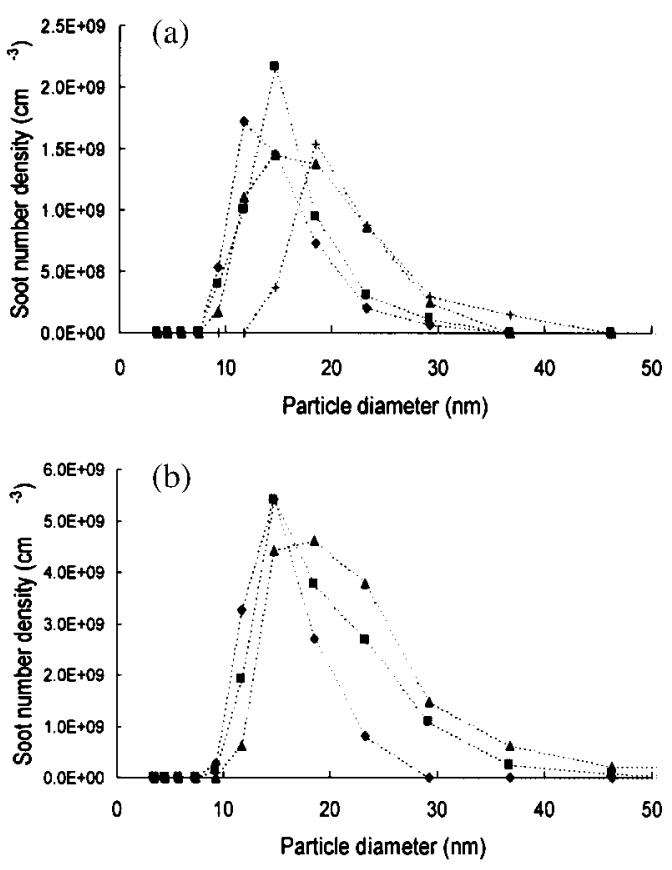

FIG. 1. Experimental soot size distributions obtained for the PFR at $1520 \mathrm{~K}$ (a) at $14.2 \mathrm{~ms}(\bullet), 16.4 \mathrm{~ms}(\mathbf{\square}), 18.5$ $\mathrm{ms}(\boldsymbol{\Lambda})$, and $20.7 \mathrm{~ms}(+)$; and $1620 \mathrm{~K}(\mathrm{~b})$ at $7.6 \mathrm{~ms}(\bullet)$, $12.0 \mathrm{~ms}(\mathbf{\square})$, and $16.4 \mathrm{~ms}(\mathbf{\Delta})$.

times from $20 \mathrm{~ms}$ to $1 \mathrm{~s}$, which also showed the measured soot particle diameter to be independent of exposure time.

Various types of grids were used [14]. The best results, based on resolution and stability under the electron beam, were obtained with Ladd lacey carbon-on-formvar (pt\#10975). Samples were obtained starting at $7.6 \mathrm{~ms}$ for the $1620 \mathrm{~K}$ condition, and at $14 \mathrm{~ms}$ for $1520 \mathrm{~K}$, which correspond to points where the soot was easily detectable and the particle sizes easily measurable. The particle sizes, which increased linearly, were extrapolated back to $9 \mathrm{~ms}$ in the $1520 \mathrm{~K}$ case in subsequent calculations. The particles for both conditions at the various residence times sampled did not differ significantly except in size. They were mainly spherical particles with very little agglomeration.

Particle sizing was accomplished using scanned images and software written [14] for MATLAB, which calculates diameters based on three userspecified points on the particle perimeters. About 150 particles were sized for each soot sample. Few agglomerates were seen; they typically contained only 2-3 primary units or particles, which were counted separately but were not statistically significant. Through focal series, images were taken to determine the degree to which focal length could distort the particle sizes. The results indicate that the present particle diameters are accurate to within $\pm 10 \%$.

The measured particle size distributions were combined with the soot mass concentration data of Marr $[9,13]$ to give number density distributions (Fig. 1). The previous soot mass data were duplicated here for the $1620 \mathrm{~K}$ condition [14], using a suction probe with filter collection, the same method used before $[9,10]$, with an average agreement to within $\pm 15 \%$. The present probe was water-cooled and had a $3.2 \mathrm{~mm}$ i.d. porous-wall inner flow tube. Nitrogen was injected through the porous wall to prevent soot deposition in the probe and to increase the quenching rate [15]. This probe quenched more rapidly than the previously used [9] larger watercooled probe without gas injection, so the effective sampling positions of the two probes were different. In order to present the data on the same timescale, the previous data are shifted $3.5 \mathrm{~ms}$ later here. Considering experimental errors in the present and previous experiments, the error ranges are approximately as follows: soot mass concentration, $\pm 15 \%$; temperature, $\pm 50 \mathrm{~K}$; mass concentration of DCMsoluble compounds, $\pm 15 \%$; stable gas species, $\pm 20 \%$.

\section{Analysis of Soot Growth Rate}

Mass growth in the PFR is surface growth dominated, that is, growth from an average soot particle size of $15 \mathrm{~nm}$ to $21 \mathrm{~nm}$ at constant number density corresponds to $84 \%$ of the observed mass increase for the $1620 \mathrm{~K}$ case. Also, oxidation can be neglected based on calculations with a full soot model [14], which show that neglecting $\mathrm{OH}$ oxidation amounts to a $17 \%$ difference in soot mass, using an $\mathrm{OH}$-soot collision efficiency of 0.2 [16]. $\mathrm{C}_{2} \mathrm{H}_{2}$ is frequently designated the soot surface growth reactant $[3,6,17]$ in models of soot formation. Surface growth rate according to the mechanism of Harris [3], which is simply $\mathrm{C}_{2} \mathrm{H}_{2}$ addition to soot but can be regarded as a global representation of a radical-based mechanism such as hydrogen-abstraction-carbon-addition (HACA) [18], is

$$
\frac{d(\text { Soot })}{d t}=k_{\text {Harris }} S P_{\mathrm{C}_{2} \mathrm{H}_{2}}
$$

where (Soot) is the mass concentration of soot, $P_{\mathrm{C}_{2} \mathrm{H}_{2}}$ is partial pressure of $\mathrm{C}_{2} \mathrm{H}_{2}$ in the atmosphere, $S$ is the surface area of soot per unit volume of gas (i.e., $S=\pi d^{2} N$, where $d$ is the average soot particle diameter and $N$ is the number concentration of soot), and $k_{\text {Harris }}$ is the specific surface growth rate constant in units of $\mathrm{g} / \mathrm{cm}^{2} \mathrm{~s}$ atm. In Harris's studies, $k_{\text {Harris }}$ declined sharply after the initial soot particle inception. This decline was shown to be a temperature-independent effect [3] and was interpreted as a decrease in the reactivity of the soot $[3,19]$. This 

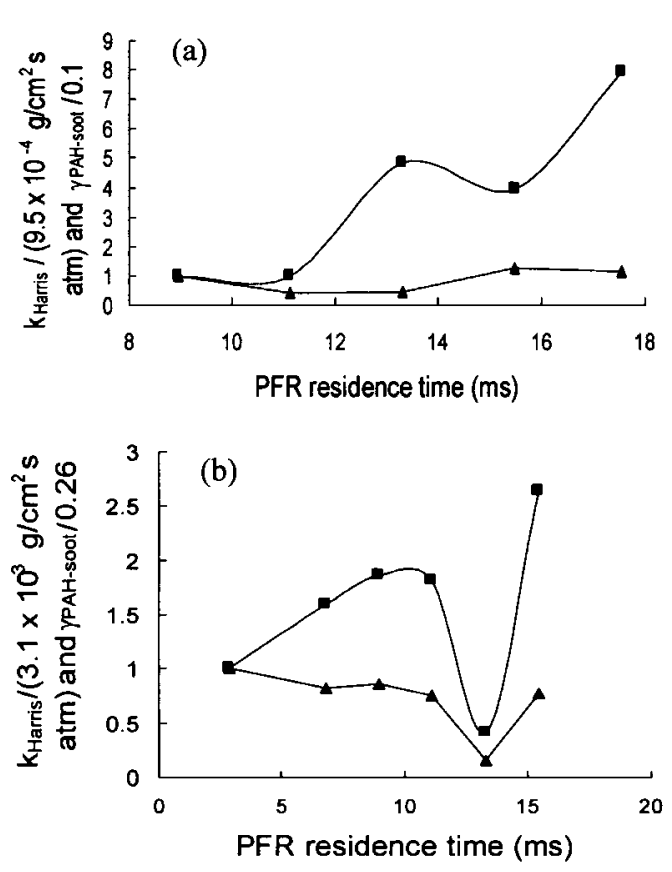

FIG. 2. Specific surface growth rate constant, $k_{\text {Harris }}$, calculated from the data for PFR at $1520 \mathrm{~K}$ (a) and $1620 \mathrm{~K}$ (b).

decline has also been observed in flames of aromatics $[5,19]$.

Figure 2 shows $k_{\text {Harris }}$ calculated for the two PFR conditions studied here. Also shown is the PAH-soot collision efficiency, $\gamma_{\mathrm{PAH}-\mathrm{soot}}$, calculated for the two cases assuming that PAH, represented by DCM soluble material, are the only growth reactants. $\gamma_{\mathrm{PAH}-\mathrm{soot}}$ and $k_{\text {Harris }}$ are comparable quantities, the PAH-equivalent of $k_{\text {Harris }}$ being $\left(M_{\mathrm{PAH}} / 2 \pi R T\right)^{1 / 2}$, where $M_{\mathrm{PAH}}$ is the characteristic molecular weight of the PAH adding to the soot and $R$ is the gas law constant. A soot density of $1.8 \mathrm{~g} / \mathrm{cm}^{3}$ was used, the number concentration was assumed to be constant and was calculated from the soot mass concentrations and diameters, and a finite difference approximation was used to obtain $d$ (Soot) $/ d t$.

The apparent reactivity indicated by $k_{\text {Harris }}$ shows a net increase with residence time and an oscillation at both temperatures. $\gamma_{\mathrm{PAH}-\text { soot }}$ shows relatively little net change at either temperature but at $1620 \mathrm{~K}$ shows an oscillation at the same residence time $(\sim 11$ to $15 \mathrm{~ms}$ ) as a larger oscillation in $k_{\text {Harris }}$. The oscillations in $k_{\text {Harris }}$ result from oscillations in $d$ (Soot)/ $d t$ that cannot be explained by changes in $S$ or $P_{\mathrm{C}_{2} \mathrm{H}_{2}}$. The relatively small change in $\gamma_{\mathrm{PAH}-\text { soot }}$, except for one oscillation (Fig. 3b), reflects the oscillations in $d($ Soot $) / d t$ being almost consistent with the variations in PAH. Oscillations of $d$ (Soot) $/ d t$, similar to those reflected in Fig. 3, occur also in 11 other sets
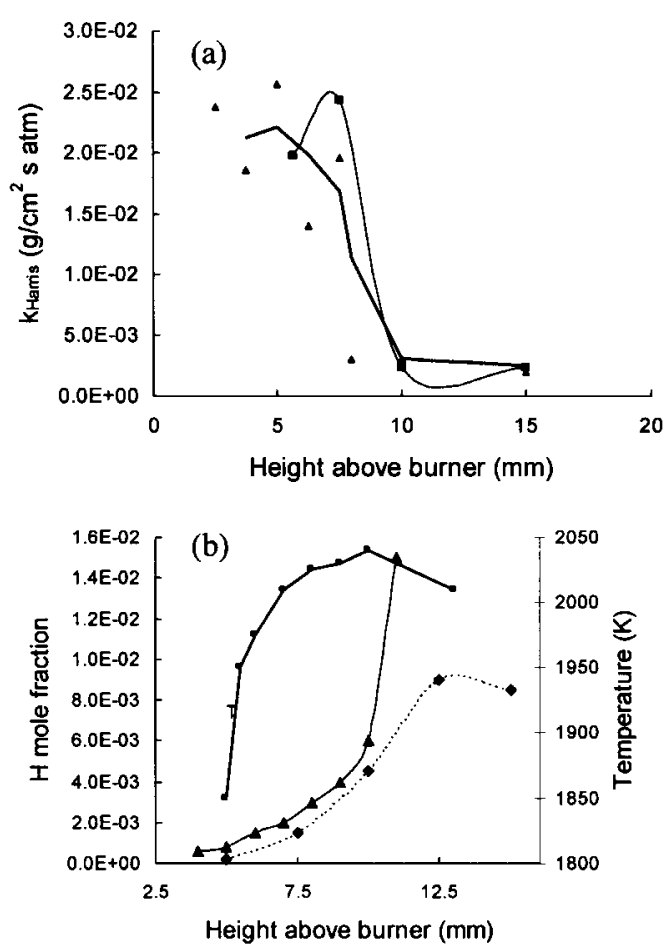

FIG. 3. (a) Calculated specific surface growth rate constant based on $\mathrm{C}_{2} \mathrm{H}_{2}$-only addition to soot in the manner of Harris [3] from data ( $)$ and from the expression derived from the PAH-only surface growth model,

$$
k_{\text {Harris }}=k_{\text {PAH-soot }} \frac{(\mathrm{PAH})}{\left[\mathrm{C}_{2} \mathrm{H}_{2}\right] \pi d^{2} N_{\mathrm{Av}} R T}
$$

(A) for the $\mathrm{C}_{6} \mathrm{H}_{6}$ flame. Data are from Grieco [31], except for particle diameters, which are from McKinnon [21]. (b) The predicted $[\mathrm{H}]$ profile for this flame $(\boldsymbol{\Delta})$, the experimental data for the $\phi=1.8, \mathrm{C}_{6} \mathrm{H}_{6} / \mathrm{O}_{2}$ flame of Bittner [22], and the temperature profile for the $\phi=2.4$ flame. Predicted $[\mathrm{H}]$ and the temperature profile are from McKinnon [21]; experimental [H] profile is from Bittner [22].

of significantly different conditions in the PFR [14]. The oscillations are not a result of random data scatter. Based on the errors (see above) in the data used, the overall error in $k_{\mathrm{Harris}}$ and $\gamma_{\mathrm{PAH}-\text { soot }}$ is significantly less than the variations seen in Fig. 3.

As has been described previously [8], the PFR is similar to the postflame zone of a premixed onedimensional flame. The region of soot formation in the PFR which shows the increase in reactivity is the early stage of soot surface growth, soon after particle inception, the same region where a decline in reactivity is observed in the premixed flame studies mentioned previously. The present particle sizes are also similar to those of premixed flame studies $(\sim 10$ to 
$20 \mathrm{~nm}$ ). Therefore, there is little reason to expect that soot should show an increase in reactivity in the PFR and a decrease in the premixed one-dimensional flames. This discrepancy casts doubt on a varying soot reactivity theory.

Decreasing concentrations of radicals, especially $\mathrm{H}$, has also been cited as the cause of the declining reactivity $[17,20]$, but this hypothesis is unacceptable for several reasons. In the PFR, the increasing apparent reactivity would require an increase in $[\mathrm{H}]$. However, in the PFR, $[\mathrm{H}]$ decays only toward equilibrium, as seen in both measurements and simulations [13], in contrast to the oscillations and net increase that would be required to give the experimental soot concentration profiles. In premixed one-dimensional aromatics flames, soot inception and the decline in apparent reactivity [5] occur while primary oxidation is still taking place and $[\mathrm{H}],[\mathrm{OH}]$, and $T$ are increasing [21-23], in conflict with the radical-based hypothesis. Even for premixed aliphatic flames, in which soot formation occurs in the burned gas region, where $[\mathrm{H}]$ and $[\mathrm{OH}]$ are decaying toward equilibrium [24,25], Colket and Hall [26] found that the decay of the apparent $\mathrm{C}_{2} \mathrm{H}_{2}$ soot growth rate constant, experimentally determined for $\mathrm{C}_{2} \mathrm{H}_{4}$ flames [3] and $\mathrm{C}_{2} \mathrm{H}_{2}$ flames [4], does not match the decay predicted by the radical-based hypothesis. This failure is due to the $[\mathrm{H}]$ and $T$ profiles not decaying in the same region nor with the same shape or magnitude as is observed for the surface growth rate constant. Faeth et al. [6,27] fitted their soot data from aliphatic flames using the surface growth mechanisms of Frenklach and Wang [17] and Colket and Hall [26], and handled the disagreement of the radical-based description of the apparent $\mathrm{C}_{2} \mathrm{H}_{2}$-addition reactivity using an adjustable factor $\alpha=0.00115 \exp (12500 / T)$ to correct for the decline in apparent reactivity not being as rapid as the decline in $[\mathrm{H}]$, the correction becoming larger as $T$ decreases. This treatment would not work for the aromatics flames where temperature and $[\mathrm{H}]$ are increasing, and it cannot account for the oscillations and net increase in apparent reactivity observed in the PFR.

Whereas the $\mathrm{C}_{2} \mathrm{H}_{2}$-addition reactivity is not constant or variable in a manner consistent with $\mathrm{C}_{2} \mathrm{H}_{2}$ actually being the soot growth reactant, such striking deviations are not seen in the PAH-addition reactivity. It has been suggested that PAH are soot growth reactants $[8,9,28,29]$, though the evidence has been inconclusive [30]. As shown below, consideration of $\mathrm{PAH}$ as the dominant soot growth reactants helps explain the behavior of the apparent $\mathrm{C}_{2} \mathrm{H}_{2}$-addition reactivity.

Based on the assumption of negligible oxidation, the expression for surface growth by PAH addition only can be written for the constant density PFR as

$$
\frac{d(\text { Soot })}{d t}=k_{\mathrm{PAH}-\mathrm{soot}}[\mathrm{PAH}][\text { Soot }] M_{\mathrm{PAH}}
$$

where ( ) refers to mass concentration, [ ] refers to molar concentration, $k_{\mathrm{PAH}-\mathrm{soot}}=\gamma_{\mathrm{PAH}-\text {-soot }} x$ (gas kinetic collision frequency), and $M_{\mathrm{PAH}}$ is the molecular weight of PAH. Assuming that the molecular weight growth of PAH proceeds solely through $\mathrm{C}_{2} \mathrm{H}_{2}$ addition,

$$
\begin{aligned}
\frac{d(\mathrm{PAH})}{d t}= & k_{\mathrm{C}_{2} \mathrm{H}_{2}-\mathrm{PAH}^{*}}\left[\mathrm{PAH}^{*}\right]\left[\mathrm{C}_{2} \mathrm{H}_{2}\right] M_{\mathrm{C}_{2} \mathrm{H}_{2}} \\
& + \text { Consumption }
\end{aligned}
$$

where $\mathrm{PAH}^{*}$ refers to $\mathrm{PAH}$ radicals, $k_{\mathrm{C}_{2} \mathrm{H}_{2}-\mathrm{PAH}^{*}}$ is the rate coefficient of $\mathrm{C}_{2} \mathrm{H}_{2}$ addition to $\mathrm{PAH}^{*}$, and Consumption is the rate of PAH consumption, which could occur by any pathway. Substituting into equation 2 the solution for (PAH), obtained by integration of equation 3 , and substituting into the resulting equation the expression for [ $\left.\mathrm{PAH}^{*}\right]$ obtained by rearranging equation 3 gives

$$
\frac{d(\text { Soot })}{d t}=\left(k_{\text {PAH-soot }} \frac{(\mathrm{PAH})}{\left[\mathrm{C}_{2} \mathrm{H}_{2}\right]}\right)\left[\mathrm{C}_{2} \mathrm{H}_{2}\right][\text { Soot }]
$$

which has the form of a surface growth rate,

$$
\frac{d(\text { Soot })}{d t}=k_{\text {apparent }}\left[\mathrm{C}_{2} \mathrm{H}_{2}\right][\text { Soot }] M_{\mathrm{C}_{2} \mathrm{H}_{2}}
$$

where

$$
k_{\text {apparent }}=\frac{k_{\mathrm{PAH}-\text { soot }}(\mathrm{PAH})}{\left[\mathrm{C}_{2} \mathrm{H}_{2}\right] M_{\mathrm{C}_{2} \mathrm{H}_{2}}}
$$

From equation 1 and equation 5 ,

$$
k_{\text {apparent }}=k_{\text {Harris }} \pi d^{2} N_{\mathrm{Av}} R T / M_{\mathrm{C}_{2} \mathrm{H}_{2}}
$$

Therefore,

$$
k_{\text {Harris }}=k_{\text {PAH-soot }} \frac{(\mathrm{PAH})}{\left[\mathrm{C}_{2} \mathrm{H}_{2}\right] \pi d^{2} N_{\mathrm{Av}} R T}
$$

Thus, $k_{\text {Harris }}$ can be expressed in terms of $k_{\mathrm{PAH}-\text { soot }}$, the justification of which, as shown by the above derivation, is that $\mathrm{C}_{2} \mathrm{H}_{2}+$ Soot is a globalization of the $\mathrm{PAH}+$ Soot pathway. Acetylene is the reactant for mass addition to $\mathrm{PAH}$, and $\mathrm{PAH}$ are the reactants for mass addition to soot. The PAH-addition mechanism can be represented as $\mathrm{C}_{2} \mathrm{H}_{2}$ addition, but with the loss of detail in eliminating the PAH intermediates.

To see if this explanation reconciles the observed deviations in the reactivity, $\gamma_{\mathrm{PAH}-\mathrm{soot}}$ and $k_{\text {Harris }}$ were calculated for two one-dimensional premixed flames: $\phi=2.4,40$ torr, $\mathrm{C}_{6} \mathrm{H}_{6} / \mathrm{O}_{2} / \mathrm{Ar}[5,31]$, and $\mathrm{C} / \mathrm{O}=$ $1.2,20$ torr, $\mathrm{C}_{2} \mathrm{H}_{2} / \mathrm{O}_{2}[2,32,33]$, for which time-resolved measurements of (PAH), (Soot), and soot diameter data are available. Figs. 3 and 4 show $k_{\text {Harris }}$ calculated from equation 1 and the values calculated from equation 6 with $\gamma_{\mathrm{PAH}-\text { soot }}=0.2$ for the $\mathrm{C}_{6} \mathrm{H}_{6}$ flame, and 0.5 for the $\mathrm{C}_{2} \mathrm{H}_{2}$ flame. $M_{\mathrm{PAH}}$ is not well 


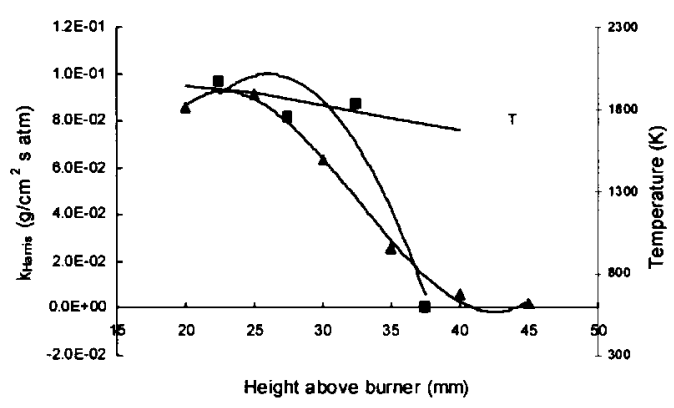

FIG. 4. Calculated specific surface growth rate constant based on $\mathrm{C}_{2} \mathrm{H}_{2}$-only addition to soot in the manner of Harris [3] from data $(\mathbf{\square})$ and from the expression derived from the PAH-only surface growth model,

$$
k_{\text {Harris }}=k_{\mathrm{PAH}-\text { soot }} \frac{(\mathrm{PAH})}{\left[\mathrm{C}_{2} \mathrm{H}_{2}\right] \pi d^{2} N_{\mathrm{Av}} R T}
$$

( $\boldsymbol{\Delta})$ for the $\mathrm{C}_{2} \mathrm{H}_{2}$ flame. The temperature profile is also shown. Data are from Wersborg [2].
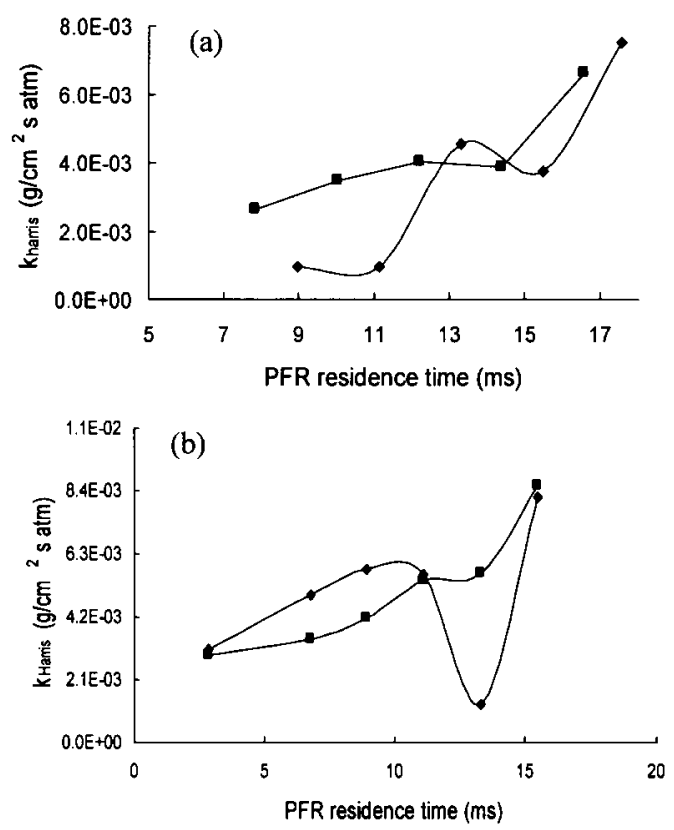

FIG. 5. Calculated specific surface growth rate constant based on $\mathrm{C}_{2} \mathrm{H}_{2}$-only addition to soot in the manner of Harris [3] from data $(\bullet)$ and from the expression derived from the PAH-only surface growth model,

$$
k_{\text {Harris }}=k_{\mathrm{PAH}-\text { soot }} \frac{(\mathrm{PAH})}{\left[\mathrm{C}_{2} \mathrm{H}_{2}\right] \pi d^{2} N_{\mathrm{Av}} R T}
$$

, $1520 \mathrm{~K}$ (a) and $1620 \mathrm{~K}$ (b). $\gamma_{\mathrm{PAH}-\text { soot }}$ values used are 0.01 for $1520 \mathrm{~K}$ and 0.02 for $1620 \mathrm{~K}$. known and is tentatively taken as constant at 500 amu for both flames. Increasing $M_{\mathrm{PAH}}$ to $900 \mathrm{amu}$ would increase $\gamma_{\text {PAH-soot }}$ for the $\mathrm{C}_{2} \mathrm{H}_{2}$ flame to 0.7 . The soot particle sizes are $2-8 \mathrm{~nm}$ for the $\mathrm{C}_{6} \mathrm{H}_{6}$ flame [5], and 5-15 nm for the $\mathrm{C}_{2} \mathrm{H}_{2}$ flame [2] for the ranges in height above burner corresponding to the peak of $k_{\text {Harris }}$ to the last points plotted.

Also shown are a $[\mathrm{H}]$ profile $[21]$ for the $\mathrm{C}_{6} \mathrm{H}_{6}$ flame and an experimental $[\mathrm{H}]$ profile for a similar $\mathrm{C}_{6} \mathrm{H}_{6}$ flame with $\phi=1.8$ [22]. As mentioned before, the radicals increase in the region of interest, obviating the radical-based interpretation of declining soot reactivity from explaining the decline in $k_{\text {Harris }}$. With no change in soot reactivity, the value of $k_{\text {Harris }}$ calculated with equation 6 declines, as is observed for $k_{\text {Harris }}$ calculated by equation 1 . The difference between $k_{\text {Harris }}$ for the two flames is about the same as that for the $\gamma_{\text {PAH-soot }}$ values, perhaps indicating a systematic difference in the soot data between the two flames. Also, these $k_{\text {Harris }}$ values are much larger than any value reported by Harris for $\mathrm{C}_{2} \mathrm{H}_{4}$ and $\mathrm{C}_{2} \mathrm{H}_{4} /$ toluene flames (peak values of $\sim 0.003 \mathrm{~g} / \mathrm{cm}^{2}$ $\mathrm{s}$ atm $[3,19]$. McKinnon [5] calculated $k_{\text {Harris }}$ values for this flame, which agree with the values calculated here.

An analysis similar to that above was done for the two PFR conditions shown before. Fig. 5 shows $k_{\text {Harris }}$ calculated by both equations for the $1520 \mathrm{~K}$ (a) and $1620 \mathrm{~K}$ (b) conditions. The best values of $\gamma_{\text {PAH-soot }}$ were found to be 0.1 for $1520 \mathrm{~K}$ and 0.2 for $1620 \mathrm{~K}$ and are held constant to illustrate the point that the PAH-soot reactivity need not vary to obtain the qualitatively observed increase in reactivity and oscillations of $k_{\text {Harris }}$ For both conditions, $k_{\text {Harris }}$ shows the oscillation at the right residence time, although the decline for $1620 \mathrm{~K}$ is not enough. In the region of the oscillation, the PFR data [8-10] show that higher molecular weight $\mathrm{PAH}$ decline more than the total DCM soluble fraction $(\sim 60 \%$ of which is naphthalene and acenaphthylene in the region of the oscillation), consistent with the notion that higher molecular weight PAH contribute more to surface growth. Fig. 6 shows gas chromatographic (GC) data for the $1620 \mathrm{~K}$ condition for naphthalene (128 amu), acenaphthylene (152 amu), cyclopenta(def)phenanthrene (190 amu), pyrene (202 amu), cyclopenta(cd)pyrene (262 amu), and total $\mathrm{PAH}$ [13]. The general trend is that higher molecular weight PAH show a larger oscillation in concentration. Also shown in Fig. 6 is the concentration of PAH reactants that would be required for $\gamma_{\mathrm{PAH}-\text { soot }}$ to remain constant to within $\pm 15 \%$. That the individual PAH measured by GC show the same decline in concentration is also evidence that the oscillations in PAH concentration are not data scatter. Instead, the oscillations may be explained by sign changes in the relatively small difference between strong formation and consumption pathways [14]. 


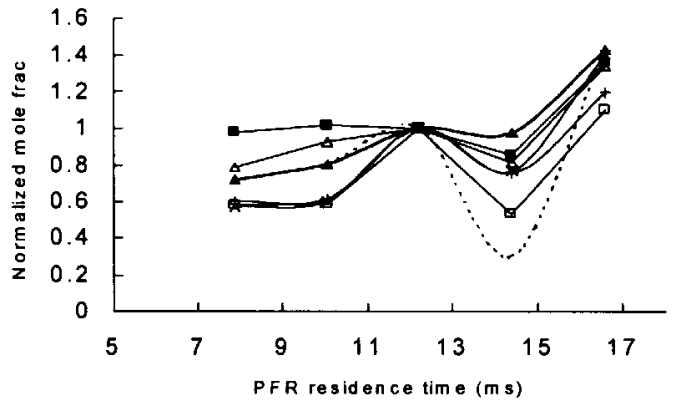

FIG. 6. PAH concentrations measured by GC analysis: naphthalene $(\boldsymbol{\square})$, acenaphthylene $(\triangle)$, cyclopenta (def)phenanthrene $(\square)$, pyrene $(+)$, cyclopenta(cd)pyrene $(\times)$, and total DCM soluble tar $(\mathbf{\Delta})$; dotted line is the required concentration profile to give $\gamma_{\mathrm{PAH} \text {-soot }}$ constant to within $15 \%$.

The values of $k_{\text {Harris }}$ from equation 6 at both 1520 $\mathrm{K}$ and $1620 \mathrm{~K}$ show not only a net increase, as observed for $k_{\text {Harris }}$ calculated using equation 1 , but also the fluctuation at the required residence time to within the finite-difference approximation. Calculations for the PFR at the present conditions with a detailed soot model [14] comparing $\mathrm{C}_{2} \mathrm{H}_{2}$ and $\mathrm{PAH}$ as soot surface growth reactants are consistent with the present finding that the soot concentration profile is best described by PAH addition. The PAHdominant surface growth mechanism explains the apparent decline in $\mathrm{C}_{2} \mathrm{H}_{2}$-soot reactivity observed in flames and reconciles the observed increases and oscillations observed in the PFR. The soot does not change in reactivity. The global $\mathrm{C}_{2} \mathrm{H}_{2}$ mechanism responds to the changes in $\mathrm{PAH}$ concentrations as predicted by equation 6 . The flame conditions analyzed here, except for the $\mathrm{C}_{6} \mathrm{H}_{6}$ flame, are not PAH-rich cases, so the observed dominance of PAH addition cannot be assumed to occur only under conditions of high PAH concentrations.

\section{Conclusion}

Extension of published PFR data to include timeresolved soot particle size measurements allowed several data sets from this system to be used along with published one-dimensional flame data to calculate time-resolved soot surface growth rates for a range of combustion conditions. Use of the results to analyze surface growth pathways shows that the soot reactivity varies with residence time in different ways in the different systems if $\mathrm{C}_{2} \mathrm{H}_{2}$ is assumed to be the dominant soot surface growth reactant. The $\mathrm{C}_{2} \mathrm{H}_{2}$-soot reactivity exhibits a sharp decline in onedimensional flames studied, with a net increase and oscillations in the PFR flames even though the soot characteristics (i.e., primary soot particles $<20 \mathrm{~nm}$ in diameter) are similar for both types of systems. The observed variations are consistent with the hypothesis that PAH are the dominant soot growth reactants. PAH exhibit concentration magnitudes and fluctuations required of the dominant surface growth reactant, and the PAH addition mechanism explains the observed variations of the apparent soot reactivity as resulting from fluctuations in PAH concentrations, with $\mathrm{C}_{2} \mathrm{H}_{2}$ addition being a globalization of the PAH-addition mechanism.

\section{Acknowledgments}

This research was supported by the EPA Center on Airborne Organics at MIT.

\section{REFERENCES}

1. Homann, K. H., and Wagner, H. G., Ber. Bunsen-Ges. Phys. Chem. 69:20 (1965).

2. Wersborg, B. L., Howard, J. B., and Williams, G. C., Proc. Combust. Inst. 14:929-938 (1973).

3. Harris, S. J., and Weiner, A. M., Combust. Sci. Technol. 32:267-275 (1983).

4. Bockhorn, H., Fettig, F., and Wenz, H. W., Ber. Bunsen-Ges. Phys. Chem. 87:1067 (1983).

5. McKinnon, J. T., and Howard, J. B., Proc. Combust. Inst. 24:965-971 (1993).

6. Xu, F., Lin, K. C., and Faeth, G. M., Combust. Flame 115:195-209 (1998).

7. Vaughn, C. B., Sun, W. H., Howard, J. B., and Longwell, J. P., Combust. Flame 84:38-46 (1991).

8. Lam, F. W., Longwell, J. P., and Howard, J. B., Proc. Combust. Inst. 22:323-332 (1989).

9. Marr, J. A., Giovane, L., Longwell, J. P., Howard, J. B., and Lafleur, A. L., Combust. Sci. Technol. 101:301-309 (1994).

10. Macadam, S., Beér, J. M., and Sarofim, A. F., Proc. Combust. Inst. 26:2295-2302 (1997).

11. Dobbins, R. A., and Megaridis, C. M., Langmuir 3:254 (1987).

12. Feitelberg, A. S., "The Effects of Metal Additives on Soot Formation," Ph.D. thesis, Massachusetts Institute of Technology, Cambridge, MA, 1990.

13. Marr, J. A., "PAH Chemistry in a Jet Stirred/Plug Flow Reactor System," Ph.D. thesis, Massachusetts Institute of Technology, Cambridge, MA, 1993.

14. Kronholm, D. F., "Molecular Weight Growth Pathways in Fuel-Rich Combustion," Ph.D. thesis, Massachusetts Institute of Technology, Cambridge, MA, 2000.

15. Lasher, S., "Ultra-fine Soot Investigation in Flames," M.S. thesis, Massachusetts Institute of Technology, Cambridge, MA, 1999.

16. Neoh, K. G., Howard, J. B., and Sarofim, A. F., in Particulate Carbon Formation during Combustion, (D. C. Siegla, and G. W. Smith, eds.), Plenum, New York, 1981, p. 261-277. 
17. Frenklach, M., and Wang, H., Proc. Combust. Inst. 23:1559-1566 (1991).

18. Frenklach, M., Clary, D. W., Gardiner, W. C., and Stein, S. E., Proc. Combust. Inst. 20:887-901 (1985).

19. Harris, S. J., and Weiner, A. M., Combust. Sci. Technol. 38:75-87 (1984).

20. Bockhorn, H., and Schäfer, T., in Soot Formation in Combustion, Springer-Verlag, Berlin, 1994, p. 253.

21. McKinnon, J. T., "Chemical and Physical Mechanisms of Soot Formation," Ph.D. thesis, Massachusetts Institute of Technology, Cambridge, MA, 1989.

22. Bittner, J. D., and Howard, J. B., Proc. Combust. Inst. 18:1105-1116 (1981).

23. Homann, K. H., Morgeneyer, W., and Wagner, H. G., in Combustion Institute European Symposium, (F. Weinberg, ed.), Academic Press, New York, 1973, p. 394-399.

24. Harris, S. J., Weiner, A. M., and Blint, R. J., Proc. Combust. Inst. 21:1033-1045 (1986).
25. Bhargava, A., and Westmoreland, P. R., Combust. Flame 113:333-347 (1998).

26. Colket, M. B., and Hall, R. J., in Soot Formation in Combustion, Springer-Verlag, Berlin, 1994, p. 417.

27. Xu, F., Sunderland, P. B., and Faeth, G. M., Combust. Flame 108:471-493 (1997).

28. Benish, T. G., Taghizadeh, K., Lafleur, A. L., and Howard, J. B., Proc. Combust. Inst. 26:2319-2326 (1997).

29. Smedley, J. M., Williams, A., and Bartle, K. D., Combust. Flame 91:71-82 (1992).

30. Kazakov, A., and Frenklach, M., Combust. Flame 112:270-274 (1998).

31. Grieco, W. J., "Fullerenes and Carbon Nanostructures Formation in Flames," Ph.D. thesis, Massachusetts Institute of Technology, Cambridge, MA, 1999.

32. Tompkins, E. E., and Long, R., Proc. Combust. Inst. 12:625-634 (1969).

33. Wersborg, B. L., Fox, L. K., and Howard, J. B., Combust. Flame 24:1-10 (1975).

\section{COMMENTS}

Bernd Bartenbach, BASF AG, Germany. Did you seriously check the mixing conditions and real plug-flow behavior in your reactor? Bad mixing might be a reason for so-called oscillations.

Author's Reply. Excellent plug-flow and mixing characteristics in this reactor have been found in previous experimental studies [Refs. 8,13 in paper].

Andrei Kazakov, Princeton University, USA. How would you explain the shape of the PAH concentration curves?

Author's Reply. The oscillation behavior of the PAH concentration profiles may be attributed to variations in the relative magnitudes of the rates of $\mathrm{PAH}$ formation and consumption. Using the same values for collision efficiencies as those used to account for all the soot surface growth by $\mathrm{PAH}$ addition, calculations show that the oscillations in the $\mathrm{PAH}$ concentration may be explained by sign changes in the relatively small difference between strong formation and consumption pathways [Ref. 14 in paper]. The uniqueness of this interpretation has not been analyzed in sufficient detail to exclude other possible interpretations.
R. A. Dobbins, Brown University, USA. Surface growth of particles by gas-phase molecular impingement results in a narrowing of the particle size distribution. The observed widening of the sizes indicates another process such as particle/particle coagulation, or possibly near particle inception, is also present. The possible impact of coagulation on the data reduction and conclusions should be checked out to be certain that its influence is small.

Author's Reply. Based on both experimental and theoretical evidence, particle-particle coagulation is not important under the conditions of the present work. Experimentally, only a small number of agglomerates, containing no more than two or three primary particles, were seen in the electron micrographs and were statistically insignificant. This observation is consistent with simple kinetic theory calculations of particle-particle collision rates in the plug flow reactor using experimentally measured soot particle sizes and concentrations. The calculated average number of collisions of a particle with other particles during passage through the reactor is essentially zero. 